\title{
Standardization of Herbal Medicine and Enforcement of Regulations in Herbal Medical System
}

\author{
Article by Saveri Raj P.X \\ $P h D$ in Alternative Medicine, Texila American University, India \\ Email: saveriraj106@gmail.com
}

\begin{abstract}
Ever since the birth of mankind there has been a relationship between life, disease, nature and herbal medicinal plants. Primitive medicine men started studying diseases and treatments through the use of nature around him. Through their intuition and by regular practice of trial and error methods, they identified and evolved a system of medical knowledge on herbal remedies. The history of herbal medicine is as old as human history.

In recent decades, there are malpractices, by some unethical herbal practitioners and herbal drug manufactures, which are injurious and at times fatal to the people. Hence the need for standardization of herbal medicine and enforcement of regulations for the same, are indispensable. This Article strives to analyze various measures of standardization, regulations and actions against malpractices in Herbal Medical System to safeguard the welfare of the people.
\end{abstract}

Keywords: Herbal Medical Systems, Standardization, Regulations, People’s welfare.

\section{Introduction}

Herbal medicines have been used since the dawn of civilization to maintain health and to treat various diseases. Seeds, leaves, stems, bark, roots, flowers, and extracts of medicinal plants have been used in herbal drugs for more than two millennia. Herbal drugs are the oldest form of health care known to mankind1. This knowledge on medical practices and traditions were transferred by word of mouth to their generations as folk medicines, and subsequently they have been recorded. Such records are available from ancient countries like India, China, Egypt and Greece. These authentic records demonstrate that the natural medicinal plants have been the main source of healing till the dawn of modern medicine. Herbal medicine system has enabled the world to survive thus far in the history of mankind. Herbal drug is a chief element in various traditional medical systems and a common component in ayurveda, siddha, naturopathy, homeopathy and other such systems2. Herbs are generally considered as safe since they belong to natural sources $\mathbf{3}$.

But now the herbal medical system is facing problems from unethical herbal drug manufacturers and unqualified herbal medical practitioners, causing injurious consequences, and sometimes fatal to the people. And many spurious herbal drugs are made available in the market by some unscrupulous persons, which cause adverse effects to the people who consume them without prescription. And there are some unethical and unqualified herbal practitioners, who cause harm to the people by dealing with insecure herbal medicines.

Therefore, there is an absolute need for standardization and regulations by the Governments concerned. The purpose of this study is to analyze the difficulties involved in the standardization in herbals medicine, and to find suitable measures for the same. Similarly, this study is to analyze the challenges towards regulations in the manufacture and distribution of herbal medicine, and how effectively they can be implemented by the Governments concerned.

\section{Method}

The method adopted for this study is a meta-analysis type of qualitative research, involving perusal of mostly published academic journals on the subject. This study was undertaken from the various 
Texila International Journal of Clinical Research

Volume 3, Issue 2, Dec 2016

resources and sites such as Pub Med, psu.edu, currentscience.ac.in, researchgate.net, caregate.net, scribed etc. with a purpose to analyze the various measures for standardization and regulations of herbal medicine.

\section{Findings of the study}

Herbal Medical System is facing challenges from within its system. There are some unqualified herbal medicine practitioners, unethical herbal medicine manufacturers. There is lack of cooperation among the Herbal doctors with 5 years of education in Herbal Medical System and the Herbal medicine healers without such qualification but have the traditional experience derived from their heirs.

There are adulterators mixing or substituting the original drug material with other spurious, inferior, defective, spoiled, useless other parts of same or different plant or harmful substances or drug which do not confirm with the official standards. Gross substitution with plant material and substitution with exhausted drugs are done in herbal medicine by some unethical herbal doctors.

Deterioration happens especially during storage, leading to the loss of the active ingredients, and the actual medicinal qualities. Physical factors such as air (oxygen), humidity, light, and temperature can bring about deterioration directly or indirectly. There are problems of incorrect storage of herbal medicines. Preservation and dosage measurement are serious problems in developing countries. The label claim and other information provided for the use of a herbal preparation may be far from what is in the container.

Some unethical and unqualified people practice herbal treatments which are injurious and fatal to the health of the patients. They engage in gross substitution of plant material, and deal with exhausted drugs

There is complex nature of herbal products and their formulation for therapeutic use. There are challenges in accurate identification of medicinal herbs; collection of authentic and genuine organic medicinal herbs; the diverse and numerous and range of herbs; constraints with clinical trials with people available for research. The preparations of herbal drugs are either as single herb or as collections of herbs in composite formulae4. This may be the main reason why quality control of oriental herbal drugs is more difficult than that of western drug. Patients use herbal drugs arbitrarily with modern medicines, as there are potential of drug interactions and increased risk of adverse drug reactions. The folkloric use of crude drugs is often empirical and is based on observation from clinical trials without experimental support. Use of heavy metals is permitted in traditional medicines but in specific concentrations, which were mentioned by ancient physicians. There are now many examples of the toxicity caused by the use of heavy metals in the preparations of traditional drugs. Lead, copper, mercury, arsenic, silver and gold that are commonly added to these preparations, have caused toxicity on many occasions.

\section{Discussion on the findings of the study}

It has to be ensured that all herbal medicines is 'evidence based' and validated by scientific research, to ensure safety and efficacy for the cure of a disease, and at the same time with least harm to the patients5. In adhering to these rulings, we have to ensure several key issues like damages and side effects caused by these medicines to the patients. Only evidence based and research based facts on the herbal medicines can safeguard the interests of the people. Therefore, it is imperative that herbal medicine should be subjected to evidence based medical system validated by scientific research.

Many research studies have been done in this field to find out which medicine plant is suitable for which disease; to study which medicinal plant is harmful to humans; nutritional values of medicinal plants; which plant has toxins harmful to humans and so on. Allocation of Government funds for research purposes has to ensure more and more evidence-based scientifically proven herbal medicine.

The preparations are either as single herbs or as collections of herbs in composite formulae. This may be the main reason why quality control of oriental herbal drugs is more difficult than that of western drug. These constraints and challenges have to be resolved to make the herbal medicine a highly effective and beneficial in local and global level.

Potential contaminants of herbal medicines include microorganisms, microbial toxins, pesticides, 
fumigation agents, radioactivity, and the presence of toxic compounds of toxic metals, which are given in the table below, and for which regulations have to be implemented by the governments concerned. In assessing toxicity of an herbal medicine, the dose chosen is very important.

Table: Potential contaminants which require regulations and monitoring in

\begin{tabular}{|l|l|l|}
\hline Si. No & $\begin{array}{l}\text { Type of } \\
\text { contaminant }\end{array}$ & Examples \\
\hline 1 & Microorganisms & $\begin{array}{l}\text { Staphylococcus aureus, } \\
\text { Escherichia coli (certain } \\
\text { strains),Salmonella, } \\
\text { Shigella, etc }\end{array}$ \\
\hline 2 & Microbial toxins & $\begin{array}{l}\text { Tabtoxin from } \\
\text { Pseudomonas syringae, } \\
\text { and trichothecenes from } \\
\text { Fusarium and other fungi } \\
\text { etc }\end{array}$ \\
\hline 3 & Pesticides & $\begin{array}{l}\text { Chlorinated pesticides, } \\
\text { phosphates, carbonate } \\
\text { insecticides, fungicides, } \\
\text { triazine herbicide, } \\
\text { naphthol etc }\end{array}$ \\
\hline 4 & Fumigation agents & $\begin{array}{l}\text { Ethylene oxide, methyl } \\
\text { bromide, etc }\end{array}$ \\
\hline 5 & Radioactivity & $\begin{array}{l}\text { Cs-134, Cs-137, Ru-103, } \\
\text { I-131, Sr-90 etc }\end{array}$ \\
\hline 6 & Metals & $\begin{array}{l}\text { Lead, cadmium, mercury, } \\
\text { arsenic etc }\end{array}$ \\
\hline
\end{tabular}

\section{The quality control of herbal medicine}

The tool primarily used to detect and quantify the elements in most toxic metal analyses is based on atomic absorption spectrometry (AAS). Currently, there have been a number of instruments developed based on the same principle, such as inductively coupled plasma-optical emission spectrometry (ICP-OES). Detection and quantification based on mass spectrometry has also been available using inductively coupled plasma-mass spectrometry (ICP-MS).

The herbs which have toxicity and have no clear evidence should be either restricted to use or banned entirely6. The herbal medicine system faces the complexity in standardizations. There are constraints with clinical trials with people available research. The herbal technology should strive for all aspects of innovation in them to improve the treatment regimens to be more cost effective and to be more patient friendly7. Recent surveys reported in the American news media indicated that a large percentage of the public would like to see products supported by science and by clinical research.

Standardization is a tool in the quality control process. Standardization means adjusting the herbal drug preparation to a defined content of a constituent or group of substances with known therapeutic activity. Standardization of herbal medicines is the process of prescribing a set of standards or inherent characteristics, constant parameters, definitive qualitative and quantitative values that carry an assurance of quality, efficacy, safety and reproducibility. It is the process of developing and agreeing upon technical standards. Standardization is the first step for the establishment of a consistent biological activity, a consistent chemical profile, or simply a quality assurance program for production and manufacturing. The lawful situation of herbal drugs varies from country to country. Developing countries have folk knowledge of herbs and their use in traditional medicine is wide spread8. 
Texila International Journal of Clinical Research

Volume 3, Issue 2, Dec 2016

\section{Conclusion}

Herbal Technology is a scientific exploration on the possible applications for conversion of medicinal plants into products for health, food and cosmetic products. Herbal Technology provides basic knowledge, applied expertise and professional skills for production of herbal medicine, food supplements and health care products. Herbal drug technology is used for converting botanical materials into medicines, where standardization and quality control with proper integration of modern scientific techniques and traditional knowledge is vital.

Clinical research is a scientific inquiry in to the aspects of health and illness in people. It is an analysis of the ways and means to prevent, diagnose and treat illness. Clinical research is a branch of healthcare science that determines the safety and effectiveness of medical devices, diagnostic tools, and 'diagnosis and treatment' of disease. Clinical research studies explore whether a medical strategy, treatment, or device is safe and effective for living beings, especially for humans.

A major factor impeding the development of the medicinal plant based industries in developing countries has been the inadequate measures standardization and regulations in the industrial utilization of medicinal plants.

It is the cardinal responsibility of the regulatory authorities to ensure that consumers get the medication with guarantees purity, safety, potency and efficacy. The regulatory authorities have to rigidly follow various standards of quality prescribed for raw materials and finished products in pharmacopoeias, formularies and manufacturing operation through statutory imposed good manufacturing practices.

Control should be exercised from the process from the beginning to the end and quality assurance along the complete process chain. Government regulations are necessary for the protection of the consumers. It may help to ensure herbal medical system has a long and healthy future. The regulations on correct medicinal plants, avoidance of adulteration and contamination, management of quality of medicinal plant products and derivatives will boost the herbal medicine system.

Stability testing of herbal drugs is a challenging risk, because the entire herb or herbal product is regarded as the active matter, regardless of whether constituents with defined therapeutic activity are known. The purpose of a stability testing is to provide proof on how the quality of the herbal products varies with the time under the influence of environmental factors such as temperature, light, oxygen, moisture, other ingredient in the dosage form, particle size of drug, microbial contamination, trace metal contamination, leaching from the container and to establish a recommended storage condition and shelf-life. Stability testing is necessary to ensure that the product is of satisfactory quality throughout its entire storage period. Stability data can also be generated under accelerated atmospheric conditions of temperature, humidity and light, which is referred to as short term stability and the data so obtained is used for predicting shelf-life of the product.

For herbal drugs and products, standardization should encompass the entire field of study from cultivation of medicinal plant to its clinical application. Standardization of methods and quality control data on safety and efficacy are required for uplifting the status and safety of herbal drugs.

Rigid requirements to ensure the safety, efficacy and quality of herbal medicine have to be enforced. Herbal medicines should acquire scientific and clinical evidence before the release to the market.

In order to assure a consistent and acceptable quality herbal product, care should be taken right from the identification and authentication of herbal raw materials to the verification process of final product9.

The government may issue directions to the local authority on matters relating to health policy, planning for health facilities, standards to be maintained, mode of administration and it shall be the duty of the local authority to carry them out10.

World Health Organization (WHO) has distinct herbal drugs as complete, labeled medicinal products that have vigorous ingredients, aerial or secretive parts of the plant or other plant material or combinations11. World Health Organization has set precise guidelines for the evaluation of the 
safety, efficacy, and quality of herbal medicines12.

In order to achieve scientific and clinical validation of botanicals and herbal preparations, there is a need to adopt approaches using chemical standardization, biological assays, animal models, and clinical trials. Existing technologies are not adequate for complete analyses of constituents. In most developing countries, the costs of analyses and standardization are still too high, especially for small manufacturers. Furthermore, the non-availability of instruments and infrastructure, expertise, and human resources has hampered progress in standardization technology. A new paradigm on the concept of standardization and therapeutic validation of herbal medicines may be required to address the issues. The major challenge to the scientific community is, therefore, to formulate a simple, affordable, and reliable standardization method or protocol to be used in the standardization of herbal products.

According to Willard, standardizing should involve the compilation of complete data on herbs such as the seasons in which the herb is harvested, the ripeness and the taste, smell, appearance, drying, storage, processing and fingerprinting which needs much larger spectrum of five or more active or market constituents 13. Standardization is also considered as the way to deal with the regulations framed by regulatory authorities that require drug measurability and the active ingredients to be stated as product labels14.

The completely finished product quality control testing will lead to the production of standardized and therapeutically effective herbal formulations. This can be achieved only if the herbal medicines are evaluated and analyzed using sophisticated modern techniques of standardization15.

In order to assure a consistent and acceptable quality herbal product, care should be taken right from the identification and authentication of herbal raw materials to the verification process of final product. The following standardization measures are recommended.

Table 2. Standardization Measures in herbals medicine, in the various stages

\begin{tabular}{|c|c|c|}
\hline Sl.No & Stage & Standardization Measures \\
\hline 1 & $\begin{array}{l}\text { Identification and } \\
\text { Authentication }\end{array}$ & $\begin{array}{l}\text { The first check is for the proper } \\
\text { identification of the plant species or } \\
\text { botanical verification by the currently } \\
\text { accepted Latin Binomial name and } \\
\text { synonyms16. It should be checked whether } \\
\text { proper records are maintained for stage of } \\
\text { collection, parts of the plant collected, } \\
\text { regional status botanical identity. }\end{array}$ \\
\hline 2 & Physical tests & $\begin{array}{l}\text { The second check is physical tests which } \\
\text { include organoleptic evaluation (sensory } \\
\text { characters such as taste, appearance, odor, } \\
\text { feel of the drug, etc.), viscosity, moisture } \\
\text { content, pH, disintegration time, } \\
\text { friability, hardness, flow ability, } \\
\text { sedimentation, and ash value. }\end{array}$ \\
\hline 3 & $\begin{array}{l}\text { Chromatographic } \\
\text { and spectroscopic } \\
\text { evaluation }\end{array}$ & $\begin{array}{l}\text { The marker compounds present in the } \\
\text { crude drug or herbal products have to be } \\
\text { verified. Markers play an important role } \\
\text { in fingerprinting of herbs. Quality of drug } \\
\text { can also be assessed by chromatographic } \\
\text { fingerprint. }\end{array}$ \\
\hline 4 & $\begin{array}{l}\text { Microbiological } \\
\text { parameters }\end{array}$ & $\begin{array}{l}\text { Elimination of microbiological } \\
\text { contamination measured as per the } \\
\text { methods described in the Romanian } \\
\text { Pharmacopoeia17, in the British }\end{array}$ \\
\hline
\end{tabular}


Texila International Journal of Clinical Research

Volume 3, Issue 2, Dec 2016

\begin{tabular}{|l|l|l|}
\hline & & Pharmacopoeia 18. \\
\hline 5 & Pesticide check & $\begin{array}{l}\text { Standard limits of pesticides have been set } \\
\text { by WHO and FAO (Food and } \\
\text { Agricultural Organization). The } \\
\text { pesticides should be checked. }\end{array}$ \\
\hline 6 & $\begin{array}{l}\text { Heavy metals } \\
\text { check }\end{array}$ & $\begin{array}{l}\text { Checking for the toxic metals such as Cu, } \\
\text { Zn, Mn, Fe, Pb and Hg19. Standardized } \\
\text { parameters like detection of heavy metals } \\
\text { such as lead, mercury, calcium and } \\
\text { pesticide residues should be checked in } \\
\text { crude drug sample. }\end{array}$ \\
\hline 7 & $\begin{array}{l}\text { Manufacture } \\
\text { stage }\end{array}$ & $\begin{array}{l}\text { The composition of any solvent or solvent } \\
\text { mixture used and the physical state of the } \\
\text { extract should be identified. The nature } \\
\text { and concentration of the solvent and the } \\
\text { physical state of the extract should be } \\
\text { verifiedzo. }\end{array}$ \\
\hline 8 & $\begin{array}{l}\text { Packaging and } \\
\text { storing stage }\end{array}$ & $\begin{array}{l}\text { All packaging materials like bottles and } \\
\text { other packaging materials should be } \\
\text { stored properly. }\end{array}$ \\
\hline 9 & $\begin{array}{l}\text { Ensure good manufacturing practices for } \\
\text { herbal medicines. }\end{array}$ \\
\hline 10 & $\begin{array}{l}\text { Herbal materials may contain } \\
\text { Sanitation } \\
\text { microbiological contaminants. And } \\
\text { during the course of harvesting and } \\
\text { processing herbal materials, herbal } \\
\text { products are prone to produce } \\
\text { microbiological contamination. Therefore } \\
\text { A high level of sanitation and hygiene } \\
\text { during manufacture is necessary }\end{array}$ \\
\hline
\end{tabular}

Solutions suggested for standardization of herbal medicine

There is a compelling need for standardization of Herbal Medical System, to safeguard people's welfare. Actions for obtaining the evidences, required for validation of traditional herbal medicinal products, should be augmented. A rigid application of Herbal Technology measures in Clinical Research is a vital requirement to uplift Herbal Medical System, to be more effectual and operative health care system. All herbal medicines should be subjected to 'evidence based' and validated by scientific research, to ensure safety and efficacy for the cure of a disease, and at the same time with least harm and side-effects to the patients. Many more research studies are required to find out the medicinal and nutritional values of herbs and which are harmful to humans.

Government allocation of funding for research purposes has to ensure that more and more evidence-based scientifically proved herbal products are available for the healthcare system of the people. The herbal medicines have to be evaluated and analyzed using sophisticated modern techniques of standardization. Research studies are required to be done on the effectiveness of medicinal plants for curing diseases. Specific standard should be assigned for experimentation and observation, which would lead to the process of prescribing a set of characteristics for each herbal medicine. The indigenous knowledge on the traditional medical practices and claims must be validated and documented about the ingredients, active constituents, and made accessible to the consumer. 


\section{Solutions suggested for regulation of herbal medicine}

The quality of all herbal medicinal products at all levels has to be ensured by rule of law. There should be stringent action on any malpractice on herbal system. The quality of the herbal products has to undergo stringent regulatory control, if herbal medicines are to assume a respected place in the contemporary health care system. Actions should be enhanced for obtaining the evidences required for validation of traditional herbal medicinal products with scientific proof of its efficacy. The completely finished products should be subjected to quality control testing for all herbal medicines. The quality of the herbal products has to undergo stringent regulatory control, if herbal medicines are to assume a respected place in the contemporary health care system. Factual labeling practice should adequately address quality aspects. Government regulations should ensure to conduct clinical researches to scientifically authenticate the herbal products.

Stability studies should be performed on at least three production batches of the herbal products for the proposed shelf-life, which is normally denoted as long term stability and is performed under natural atmospheric conditions. Stability testing should be conducted on the dosage form packaged in the container closure system proposed for marketing. Governments must update the databases, containing reports of investigations and clinical studies on herbal technology and herbal medicine.

These measures for standardization and the regulatory policies can effectively protect the citizens from the identified problems. When all these issues are implemented potential prospects exist for widespread use of herbal medicine as a safe, effective, and affordable form of healthcare. The above measures of standardization and of Herbal Medicines and enforcement of regulations are bound to ensure the Herbal Medical System, to serve and strive towards perfection and benefit of the humanity worldwide.

\section{References}

[1]. Abhishek, K; Ashutosh, M and Sinha, BN (2006), "Herbal drugs- present status and efforts to promote and regulate cultivation”, The Pharma Review, 6, 73-77.

[2]. Abhishek, K; Ashutosh, M and Sinha, BN, "Herbal drugs- present status and efforts to promote and regulate cultivation”, Pharma Review, 2006 6, 73-77.

[3]. Bodhisattwa Maiti et al., "Recent Trends in Herbal Drugs: A Review", International Journal of Drug Research and Technology, 2011,Vol.1 (1),17-25

[4]. British Pharmacopoeia, Vol. IV, Appendix XVI B, A356-A363 (2005).

[5]. Good Manufacturing Practices for pharmaceutical products, In: WHO Expert Committee on Specifications for Pharmaceutical Preparations. Thirty-second report. Geneva, World Health Organization, 1992:14-59 (WHO Technical Report Series, No. 823).

[6]. H. Wagner, et al, "Handbook of Medicinal Plants”, Chapter 21, Haworth Medical Press, Binghamton (2001).

[7]. Harish, P (2001), "Herbal drugs", Current Science, 81(1), 15

[8]. M.Mosihuzzaman and M. Iqbal Choudhary, "Protocols On Safety, Efficacy, Standardization, And Documentation Of Herbal Medicine”, Pure Applied. Chemistry, Vol. 80, No. 10, Pp. 2195-2230, 2008. Doi:10. (IUPAC Technical Report)

[9]. Page LR, “Whole Herbs or Standardized Plant Constituents?”, Total Health Journal, 2001,23(4):20.

[10]. Report by David R. and Walker, B, "Regulation of Herbal Medicines and Practitioners”, March 2015.

[11]. Romanian Pharmacopoeia X, Chap. IX, Ed, Medicala, Bucuresti (1993).

[12]. Satarupa Banerjee and Analava Mitra, "Changing Landscape of Herbal Medicine: Technology Attributing Renaissance”, International Journal of Pharmacy and Pharmaceutical Sciences, Vol.4,Supl.1, 2012

[13]. Sukhdev, S; Arun, N and Kalia, AN (2008), "Patentability of herbal products: A review", The Pharma Review, 4,118-124.

[14]. The Madras Public Health Act 1939 \& The Travancore-Cochin Public Health Act 1955.

[15]. Vardana Garg et al., "Facts about Standardization of Herbal Medicine: A Review", Journal of Chinese Integrative Medicine, October 2012, Vol.10, No.10.

[16]. WHO technical report series, "Guidelines for the Assessment of Herbal Medicines”, 1996, 863, 178-184. 
Texila International Journal of Clinical Research

Volume 3, Issue 2, Dec 2016

[17]. WHO Global Survey, "National Policy on Traditional Medicine and Regulation of Herbal Medicines", World Health Organization Geneva, May 2005, 168 pages.

[18]. Willard T, "Edible and Medicinal Plants of the Rocky Mountains”, Calgary, Wild Rose College of Natural Healing,1996.

[19]. WHO guidelines on safety monitoring of herbal medicines in pharmacovigilance systems, World Health Organization, Geneva, 2004

[20]. Winslow, L; Kroll, DJ (1998), “Herbs as Medicines, Archives of Internal Medicine”, 158, 2192-2199. 